\title{
"Panda smiled again - Credit goes to repeated early stage computed tomography scan: An interesting case report"
}

\author{
Manish Jaiswal, Ashok Gandhi, Devendra Purohit, R.S. Mittal \\ Department of neurosurgery, SMS medical college and hospital \\ JLN Marg, Jaipur (302004), Rajasthan, INDIA
}

\begin{abstract}
Extradural hematoma (EDH) is considered to be a rare in head trauma associated with arrested hydrocephalus, and represents a serious pathology from which complete recovery can be expected if urgent intervention done in time. In this case report, the authors present an arrested hydrocephalus patient who was apparently asymptomatic at the time of hospital admission with a mild head injury and developed rapidly increasing size of $\mathrm{EDH}$. The value of repeated early Computed tomography (CT) scan and the pathogenesis of rapidly increasing size of EDH in arrested hydrocephalic patient are discussed.
\end{abstract}

Key words: EDH; arrested hydrocephalus; repeated early stage CT scan.

\section{Introduction}

Extradural hematoma (EDH) is considered to be a rare in head trauma associated with arrested hydrocephalus, and represents a serious pathology from which complete recovery can be expected if urgent intervention done in time. In this case report, the authors present an arrested hydrocephalus patient who was apparently asymptomatic at the time of hospital admission with a mild head injury and developed rapidly increasing size of EDH. The value of repeated early Computed tomography (CT) scan and the pathogenesis of rapidly increasing size of EDH in arrested hydrocephalic patient are discussed.

\section{Case report}

A 38 year old man was admitted after road traffic accident. He was conscious but had mild symptom of giddiness but Glassgow coma scale (GCS) was 15. CT head was performed, which revealed arrested hydrocephalus with left temporo-parietal thin Extradural haematoma (EDH), an interesting finding was smiling panda face appearance in CT head due to dilated lateral ventricle (Figure 1). Urgent repeat early stage CT head was done, revealing increased size of EDH causing distortion of the previous panda face giving punched panda face appearance (Figure 2) with midline shift. Urgent surgical intervention done and patient regained consciousness. Next day post-operative CT head shown again smiling face of panda 
(Figure 3) and no mid line shift. Patient was conscious and no neurological deficit at the time of discharge $5^{\text {th }}$ day post operatively.

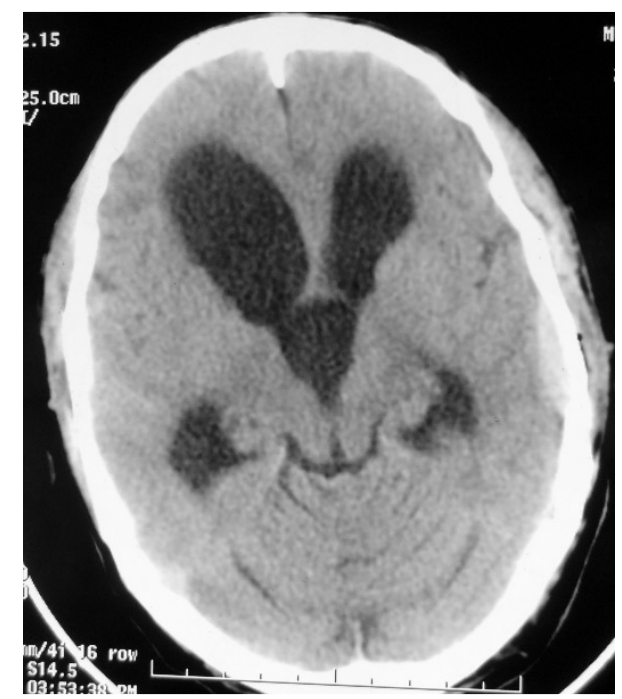

Figure 1 - "Smiling Panda face appearance" at the time of admission in CT Scan

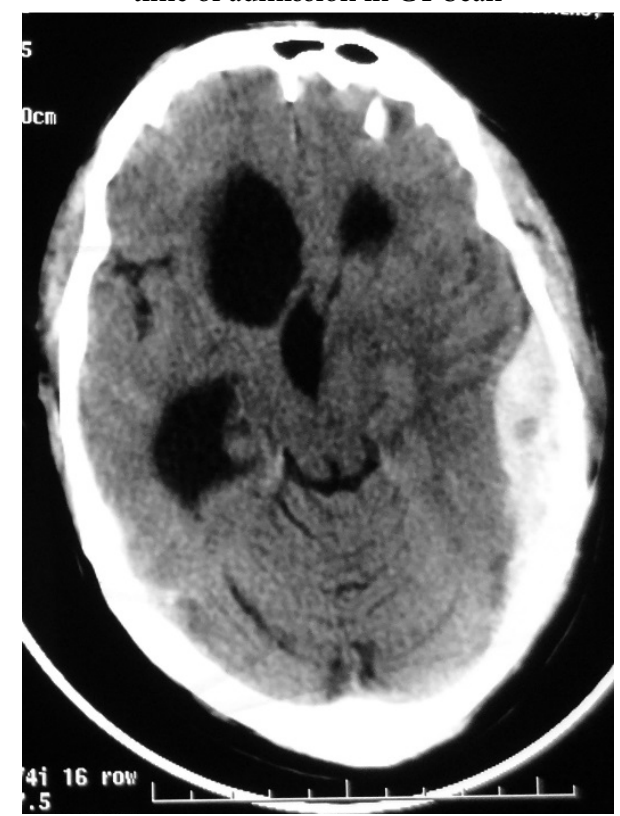

Figure 2 - "Punched Panda face appearance: 6 hours after admission in CT Scan

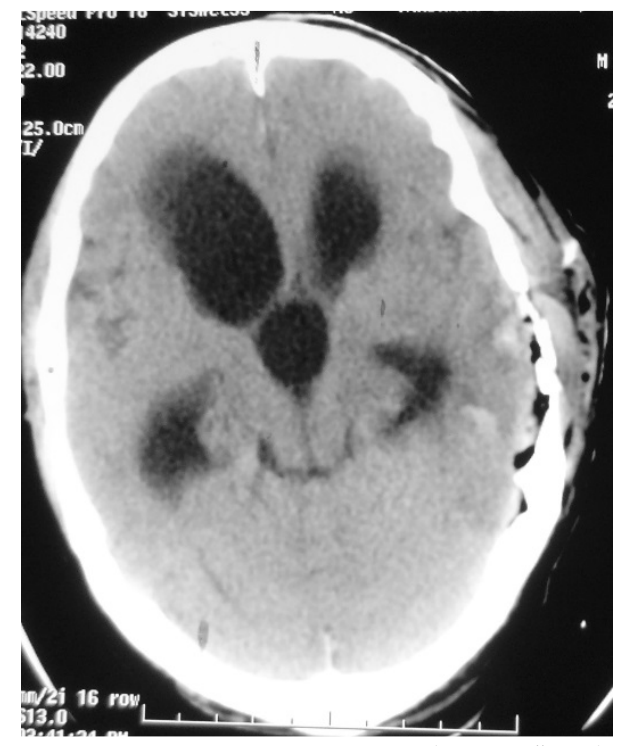

Figure 3 - Post operative CT scan showing "Smiling Face" again

\section{Discussion}

Extradural haematoma occurs in approximately $2 \%$ of all patients with head injuries and $5-15 \%$ of patients with fatal head injuries. EDH is considered to be one of the most serious complications of head injury, requiring immediate diagnosis and surgical intervention. Incidence of deleyed extradural haematoma is reported in $10-30 \%$ (1). The risk factors for increasing EDH size include lowering of intracranial pressure medically and /or surgically, thus reducing the temponading effect, rapid correction haemodyanamic shock and coagulopathies (2). But in our patient there was incidental finding of dialeted ventricles along with left temporoparietal bone fracture and thin EDH. Because there was no sign and symptom of raised intracranial pressure so it was assumed the case of arrested hydrocephalus and so 
DOI: 10.2478/romneu-2014-0052

there was no tamponading effect over dura to prevent further increase in size of $\mathrm{EDH}$, which result in rapid evolution of $\mathrm{EDH}$ causing finally mass effect and manifesting as rapid neurological deterioration of patient. Broader indications for computed tomographic (CT) scanning allow the early detection and treatment of an extradural hematoma (3). Importance of follow-up CT scans at an early stage in cases which showed rapid deterioration within a few hours after head injury has been studied $(4,5,6)$ and proven worthy in term of saving life as in our case.

\section{Conclusion}

Take home message is that "Always perform repeat early stage CT scan head in case of head injury associated with arrested hydrocephalus even there is no neurological deterioration and thus may be of value in detecting changes at an early stage to save life."

\section{Correspondence}

Manish Jaiswal

A 33/48 A 2, Omkareshwar, Varanasi, 221001,

Uttar Pradesh, INDIA

Phone - 091-9799980494, E- mail -

manishmlnmc@gmail.com

\section{References}

1. Borovich B, Braun J, Guilburd JN, et al. delayed onset of traumatic extradural haematoma. J Neurosurg. 1985;63:30-4

2. Chandra PS, Jaiswal A, Mahapatra AK. Bifrontal epidural haematomas following surgery for occipital falcine meningioma:An unusual complication of surgery in the prone position. J Clin Neurosci. 2002;9:582-4

3. Bor Seng Shu E, de Almeida Leme RJ, Aguiar PH, de Andrade AF, Teixeira MJ, Plese JP.Traumatic acute giant epidural hematoma in a hydrocephalic shunted child. Pediatr Neurosurg. 2000 Apr;32(4):176-9.

4. Servadei F, Staffa G, Morichetti A, Burzi M, Piazza G.Asymptomatic acute bilateral epidural hematoma: results of broader indications for computed tomographic scanning of patients with minor head injuries. Neurosurgery. 1988 Jul;23(1):41-3.

5. Lesoin F, Viaud C, Giraldon JM, Clarisse J, Jomin M. Delayed traumatic intracranial hematomas. Value of computer tomography. Neurochirurgie. 1982;28(6):3738.

6. Yoshimizu N, Hiramoto M, Notani M.Study of those cases which showed rapid deterioration within a few hours after head injury--importance of follow-up CT scans at an early stage. Neurosurg Rev. 1989;12 Suppl 1:175-7. 